\title{
Eradication of the chytrid fungus Batrachochytrium dendrobatidis in the Japanese giant salamander Andrias japonicus
}

\author{
Yumi Une $^{1, *}$, Kumi Matsui $^{2}$, Kenichi Tamukai $^{1,3}{ }^{,}$Koichi Goka ${ }^{4}$ \\ ${ }^{1}$ Laboratory of Veterinary Pathology, Azabu University, 1-17-71 Fuchinobe, Chuo-ku, Sagamihara, Kanagawa 252-5201, \\ Japan \\ ${ }^{2}$ Laboratory of Physiology, Azabu University, 1-17-71 Fuchinobe, Chuo-ku, Sagamihara, Kanagawa 252-5201, Japan \\ ${ }^{3}$ Denenchofu Animal Hospital, 2-1-3 Denenchofu, Ota-ku, Tokyo 145-0071, Japan \\ ${ }^{4}$ National Institute for Environmental Studies, 16-2 Onogawa, Tsukuba, Ibaraki 305-8506, Japan
}

\begin{abstract}
The purpose of this study was to establish a method for eradicating a chytrid fungus (Batrachochytrium dendrobatidis; Bd) from the Japanese giant salamander Andrias japonicus. The emerging agent $(B d)$ has a high rate of detection in this endangered amphibian species, which is designated as a special natural monument in Japan. Four Japanese giant salamanders with $B d$ confirmed by PCR assay were bathed in $0.01 \%$ itraconazole for $5 \mathrm{~min}^{-1}$ over 10 successive days. PCR assays were conducted prior to treatment, on Days 5 and 10 of treatment, and on Days 7 and 14 post-treatment. By treatment Day 5, all individuals tested negative for $B d$ and remained negative until the end of the experiment. No side effects associated with itraconazole were observed. The present method appears to be a safe and effective approach for $B d$ eradication and may contribute to reducing the threat and spread of $B d$ among endangered amphibians. Notably, this study represents the first reported $B d$ eradication experiment involving Japanese giant salamanders.
\end{abstract}

KEY WORDS: Eradication $\cdot$ Chytrid fungus $\cdot$ Japanese giant salamander

\section{INTRODUCTION}

The chytrid fungus Batrachochytrium dendrobatidis $(B d)$, the causative agent of chytridiomycosis, has been implicated in the widespread decline of amphibian populations and is currently the greatest pathogenic threat to amphibian biodiversity (Berger et al. 1998, Daszak et al. 1999, Lips et al. 2006, Skerratt et al. 2007, Young et al. 2007). From a conservation standpoint, many international organizations, such as the International Union for Conservation of Nature (IUCN), consider $B d$ to be an important emerging pathogen of wild amphibians. Conse- quently, these organizations are promoting the Amphibian Ark project (ex situ conservation), which aims to protect rare amphibians facing threats such as $B d$ that cannot currently be mitigated in the wild (Amphibian Ark 2011). For ex situ conservation, it is important to establish safe and effective methods for the detection and eradication of $B d$.

Japan, which is located in the mid-latitudes and has a temperate climate, has long been geologically isolated from mainland Asia. This isolation has resulted in a high diversity of amphibians, including 23 species in the order Urodela and 35 species in the order Anura that are native to Japan. Of these spe- 
cies, $49(84 \%)$ are endemic and $36(62 \%)$ are listed as threatened by the Japanese Ministry of the Environment (Ota 2000). In 2006, chytridiomycosis was confirmed for the first time in Asia when it was implicated in the death of captive amphibians in Japan (Une et al. 2008). A $B d$ survey among wild amphibians conducted soon after this initial detection revealed a high rate of infection among Japanese giant salamanders Andrias japonicus (Goka et al. 2009), which have been designated as a special natural monument and are completely protected in Japan, as are a number of their known habitats. A. japonicus is also listed as a CITES Appendix I species (Kaneko \& Matsui 2004). The present study aimed to establish a safe and effective method for eradicating $B d$ in the Japanese giant salamander.

Although a number of methods for eradicating $B d$ have been reported to date (Parker et al. 2002, Woodhams et al. 2003, Forzán et al. 2008, Bishop et al. 2009, Garner et al. 2009, Nichols \& Lamirande 2009, Berger et al. 2010, Martel et al. 2011), most of these reports have focused on anuran taxa. However, several groups have recently reported methods for treating chytridiomycosis in urodeles. Among them is heat treatment for groups of hellbenders (Wanner 2008, J. Briggler pers comm). Here, we conducted $B d$ eradication experiments following the method used in our successful treatment of chytridiomycosis in the urodele Ambystoma tigrinum (Tamukai et al. 2011).

\section{MATERIALS AND METHODS}

Four Japanese giant salamanders (average body mass $=1318 \mathrm{~g}$ ) that were naturally infected with $B d$ were used in this study (Table 1). The salamanders, which appeared to be in good health, were housed individually in tanks containing freshwater in rooms maintained at $15^{\circ} \mathrm{C}$. Prior to treating the $B d$ infection, swabs were collected from the ends of the animals' toe tips and PCR assays for the detection of $B d$ were performed in duplicate, as described below. As a preliminary experiment, the following 7 areas on the body of the giant salamanders were swabbed to obtain the DNA samples for the nested PCR analysis: (1) eye and mouth, (2) abdomen, (3) cloaca and tail, and (4) tips of each of the 4 toes. Because the toe tips showed the highest rates of $B d$ infection, this area was selected for subsequent sampling in the main experiment. $B d$ infection was treated using an aqueous solution of itraconazole prepared by diluting a $1 \%$ itraconazole oral solution (Janssen Pharmaceutical K.K.) with water from the tanks used to house the salamanders, to a final concentration of $0.01 \%$. Animals were placed into $700 \times 800 \mathrm{~mm}$ plastic bags and $1000 \mathrm{ml}$ of the drug solution was poured into each bag, which was then gently agitated. The animals were kept in the bags for 5 min to ensure that the drug solution reached all parts of the body. One corner of the plastic bags was then cut to drain the drug solution from the bag, before a larger cut was made and the animals were gently returned to their tanks. The $B d$ eradication protocol consisted of treatment by immersion in the drug solution for 5 min once a day for a total of $10 \mathrm{~d}$. Fresh itraconazole solution was made up for each individual animal on each day and the solution was disposed of after use to reduce the probability of spreading the infection. In addition, the drug have been diluted, or altered.

Changes in clinical signs, including appetite, reaction to irritation and skin pigmentation, were monitored during the course of the itraconazole treatment, and nested PCR assays were conducted to measure the effectiveness of itraconazole treatment. Nested PCR assays for $B d$ were performed using samples isolated by swabbing the toe tips of salamanders with cotton swabs and using a primer for the $B d$ internal transcribed spacer (ITS) gene region, as described by Goka et al. (2009). The nested PCR assays were performed at 5 time points: pre-treatment, Days 5 and 10 during treatment, and Days 7 and 14 post-treatment.

Table 1. PCR test results (pre- and post-experiment) for the presence of Batrachochytrium dendrobatidis in the Japanese giant salamander Andrias japonicus. Forefeet and hindfeet samples were taken from the toe tips. ++: Strong positive; +: positive; -: negative

\begin{tabular}{|lcccccccc|}
\hline \multirow{2}{*}{ Animal no. } & \multicolumn{2}{c}{ Forefeet } & \multicolumn{2}{c}{ Hindfeet } & \multicolumn{2}{c}{ Pre-experiment (8 Jul) } & \multicolumn{2}{c}{ Post-experiment (15 Aug) } \\
& Right & Left & Right & Left & Length (cm) & Body mass (g) & Length (cm) & Body mass (g) \\
\hline 1 & ++ & ++ & ++ & ++ & 62 & 1450 & 64.3 & 1780 \\
2 & ++ & ++ & ++ & ++ & 56 & 1070 & 6.5 & 1500 \\
3 & - & - & ++ & ++ & 60 & 1450 & 1820 & 1300 \\
4 & ++ & ++ & + & ++ & 59 & 1300 & 59.8 \\
\hline
\end{tabular}




\section{RESULTS}

The results of the PCR assay and the profiles of the 4 animals are shown in Table 1. All 4 of the animals tested positive for $B d$ in the pre-treatment PCR tests, and $B d$ was observed in samples of sloughed skin collected from the toe tips before the beginning of the fungus eradication experiment (Fig. 1). After the fifth bath in the $0.01 \%$ aqueous itraconazole solution, all of the samples $(n=16)$ tested negative for $B d$ and remained negative until the final PCR assay was performed at Day 14 post-treatment. The animals exhibited normal vitality and appetite throughout the treatment period, and all had gained mass by the end of the experiment (Table 1). Importantly, no changes in body color or accelerated sloughing of skin were observed over the course of the experiment.

\section{DISCUSSION}

$B d$ is the causative agent of chytridiomycosis and is one of the most pathogenic microorganisms affecting amphibians in both captivity and in nature (Berger et al. 1998, Parker et al. 2002). The establishment of stable, $B d$-free, captive populations is one of the emergency conservation measures currently being considered to save threatened amphibian species from extinction (Amphibian Ark 2011). The effective and safe eradication of $B d$ is necessary in order to prevent mortality in captive colonies, reduce the risk of the disease spreading, and better manage the disease in

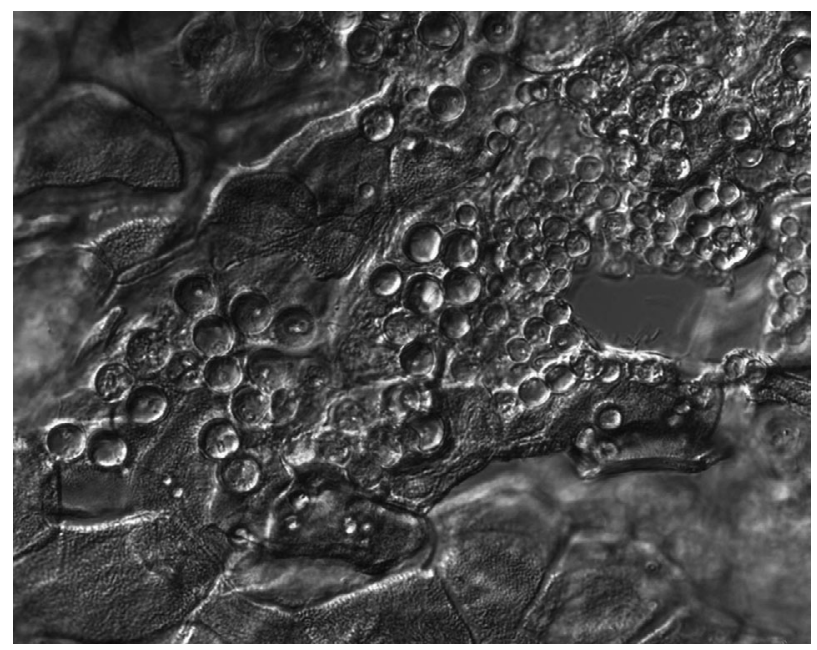

Fig. 1. Batrachochytrium dendrobatidis on skin sloughed from a Japanese giant salamander Andrias japonicus. The specimen is unstained. Photo credit: Dr. Shigeki Inaba (National Institute of Technology and Evaluation) threatened wild populations (Berger et al. 2010). The present study was therefore conducted with the objective of establishing a simple, effective and safe $B d$ eradication program for the Japanese giant salamander, which is a rare and protected species in Japan.

A number of $B d$ eradication initiatives have been proposed (Parker et al. 2002, Woodhams et al. 2003, Forzán et al. 2008, Bishop et al. 2009, Garner et al. 2009, Berger et al. 2010, Martel et al. 2011). One method exploits the low heat resistance of $B d$ (Woodhams et al. 2003), whereas others using formalin and malachite green have also been reported (Hohreiter \& Rigg 2001, Parker et al. 2002). Although a variety of antifungal agents have been shown to be effective for $B d$ eradication in several amphibian species (Forzán et al. 2008, Garner et al. 2009, Nichols \& Lamirande 2009, Berger et al. 2010, Martel et al. 2011), Briggler reported that itraconazole is not particularly well suited to treating $B d$ infection as it rarely killed $B d$ after long-term exposure, but heat treatment was more effective on an aquatic salamander (J. Briggler pers. comm.). However, the use of heat cannot be readily applied for amphibians, particularly urodeles such as the Japanese giant salamander, which has a low tolerance to elevated temperatures. As the effects of drugs are likely to vary during different developmental stages, the effectiveness and side effects of antifungal agents have generally been evaluated using tadpoles, which are relatively more sensitive to changes in water chemistry (Garner et al. 2009, Berger et al. 2010, Martel et al. 2011). However, with the exception of a study by Tamukai et al. (2011) which evaluated the efficacy of itraconazole for the treatment of chytridiomycosis, no known studies have shown that antifungal agents are effective for treating urodeles.

The physiology and structural characteristics of urodele skin differ from that of anurans (Warburg et al. 1994), and it is unknown whether the methods that are typically used to administer drugs used in anurans are appropriate for use with urodeles. The present study therefore followed the methodology of Tamukai et al. (2011), using baths consisting of a $0.01 \%$ aqueous solution of itraconazole, which was considered to be both safe and effective. Moreover, to reduce the stress associated with the bath treatment and decrease the potentially adverse effects of the drug on the animals, we devised a treatment regimen consisting of short immersion periods performed relatively more frequently. In addition, although some studies have used histopathological methods to determine the effectiveness of treatment 
(Forzán et al. 2008, Nichols \& Lamirande 2009), we adopted the more sensitive assay of nested PCR to assess eradication effectiveness. The findings of this study revealed that $B d$ was no longer detected in the 4 salamanders studied by Day 5 of the treatment.

As has been observed in tadpoles of the Mallorcan midwife toad Alytes muletensis, a potential side effect of itraconazole in amphibians is the loss of skin coloration, suggesting liver toxicity (Garner et al. 2009). In addition, corneal ulcers, kidney disease and death have also been reported in some species (Conservation Breeding Specialist Group 2010). Fluconazole appears to be safe for use in tadpoles, but its efficacy is considered to be low (Berger et al. 2010). In this study, none of the animals displayed any changes in body color and the body mass of all individuals increased by 110 to $140 \%$ by the end of the study. Taken together, these findings imply that itraconazole has no obvious side effects in the Japanese giant salamander.

Itraconazole, which is a member of the triazole family, is lipid-soluble and is therefore believed to have low solubility in water (Martin 1999). Here, we facilitated the administration of itraconazole by using a preparation of the drug intended for oral administration. In addition, the use of plastic bags for immersing the salamanders in the drug solution avoided injury to the animals. Using this method, we were able to eradicate $B d$ from animals weighing as much as $1000 \mathrm{~g}$ or more using only $1000 \mathrm{ml}$ of drug solution. We therefore conclude that the technique described in this study is a simple, inexpensive treatment method that is both safe and effective.

To evaluate the efficacy of itraconazole treatment more thoroughly, it would have been preferable to extend the monitoring phase of this experiment to at least $30 \mathrm{~d}$. However, because of the limited time available for this experiment, monitoring could only be performed for $14 \mathrm{~d}$ after treatment. For this reason, we cannot be absolutely certain that the chytridiomycosis infection was completely eradicated. However, as information on the eradication of this disease in urodele amphibians is currently limited, the results of this study are considered to be an important contribution towards the eradication and treatment of chytridiomycosis in urodeles (Tamukai et al. 2011).

Acknowledgements. We thank Janssen Pharmaceutical K.K. (Tokyo) for providing us with the itraconazole oral solution $1 \%$. This study was supported by the Global Environment Research Fund (F-3 and F-081, Leader: K.G.) of the Ministry of the Environment, Japan, 2008. It was also partially supported by the Azabu University, and a Grant-in-Aid for Scientific Research C (20580347).

\section{LITERATURE CITED}

Amphibian Ark (2011) Chytrid fungus. Available at www.amphibianark.org/the-crisis/chytrid-fungus/

> Berger L, Speare R, Daszak P, Green DE and others (1998) Chytridiomycosis causes amphibian mortality associated with population declines in the rain forests of Australia and Central America. Proc Natl Acad Sci USA 95: 9031-9036

- Berger L, Speare R, Pessier A, Voyles J, Skerratt LF (2010) Treatment of chytridiomycosis requires urgent clinical trials. Dis Aquat Org 92:165-174

Bishop PJ, Speare R, Poulter R, Butler M, Speare BJ, Hyatt $\mathrm{AD}$, Olsen $\mathrm{VH}$ (2009) Elimination of the amphibian chytrid fungus Batrachochytrium dendrobatidis by Archey's frog Leiopelma archeyi. Dis Aquat Org 84: 9-15

Conservation Breeding Specialist Group (2010) A manual for control of infectious diseases in amphibian survival assurance colonies and reintroduction programs. Available at www.cbsg.org/cbsg/workshopreports/26/ amphibian_disease_manual.pdf

$>$ Daszak P, Berger L, Cunningham AA, Hyatt AD, Green DE, Speare R (1999) Emerging infectious diseases and amphibian population declines. Emerg Infect Dis 5: 735-748

Forzán MJ, Gunn H, Scott P (2008) Chytridiomycosis in an aquarium collection of frogs: diagnosis treatment and control. J Zoo Wildl Med 39:406-411

Garner TWJ, Garcia G, Carroll B, Fisher MC (2009) Using itraconazole to clear Batrachochytrium dendrobatidis infection, and subsequent depigmentation of Alytes muletensis tadpoles. Dis Aquat Org 83:257-260

Goka K, Yokoyama J, Une Y, Kuroki T and others (2009) Amphibian chytridiomycosis in Japan: distribution, haplotypes and possible route of entry into Japan. Mol Ecol 18:4757-4774

> Hohreiter DW, Rigg DK (2001) Derivation of ambient water quality criteria for formaldehyde. Chemosphere 45: 471-486

Kaneko Y, Matsui M (2004) Andrias japonicus. IUCN Red List of Threatened Species, Version 2011.2. Available at www.iucnredlist.org/apps/redlist/details/1273/0

Lips KR, Brem F, Brenes F, Reeve JD and others (2006) Emerging infectious disease and the loss of biodiversity in a Neotropical amphibian community. Proc Natl Acad Sci USA 103:3165-3170

Martel A, Van Rooij P, Vercauteren G, Baert K and others (2011) Developing a safe antifungal treatment protocol to eliminate Batrachochytrium dendrobatidis from amphibians. Med Mycol 49:143-149

Martin S (1999) Itraconazole. Compend Contin Educ Pract Vet 21:145-147

Nichols DK, Lamirande EW (2009) Successful treatment of chytridiomycosis. FrogLog 2001:46

$>$ Ota H (2000) Current status of the threatened amphibians and reptiles of Japan. Pop Ecol 42:5-9

> Parker JM, Mikaelian I, Hahn N, Diggs HE (2002) Clinical diagnosis and treatment of epidermal chytridiomycosis in African clawed frogs (Xenopus tropicalis). Comp Med 52:265-268

Skerratt LF, Berger L, Speare R, Cashins S and others (2007) Spread of chytridiomycosis has caused the rapid global decline and extinction of frogs. EcoHealth $4: 125-134$ 
Tamukai K, Une Y, Tominaga A, Suzuki K, Goka K (2011) Treatment of spontaneous chytridiomycosis in captive amphibians using itraconazole. J Vet Med Sci 73: 155-159

- Une Y, Kadekaru S, Tamukai K, Goka K, Kuroki T (2008) First report of spontaneous chytridiomycosis in frogs in Asia. Dis Aquat Org 82:157-160

Wanner M (2008). Husbandry, captive propagation, and behavior of hellbenders. www.caudata.org/cig/project5. html (accessed 12 Jun 2011)

Editorial responsibility: Alex Hyatt, Geelong, Victoria, Australia
Warburg MR, Lewinson D, Rosenberg M (1994) Ontogenesis of amphibian epidermis. In: Heatwole H, Barthalmus GT (eds) Amphibian biology, Vol. 1. Surrey Beatty and Sons, Chipping Norton, p 33-62

Woodhams DC, Alford RA, Marantelli G (2003) Emerging disease of amphibians cured by elevated body temperature. Dis Aquat Org 55:65-67

Young S, Berger L, Speare R (2007) Amphibian chytridiomycosis strategies for captive management and conservation. Int Zoo Yearb 41:85-95

Submitted: June 16, 2011; Accepted: January 11, 2012

Proofs received from author(s): March 13, 2012 